\title{
PENNSYLVANIA'S METHOD OF SOLVING THE PROBLEM OF TOOTH DECAY AMONG SCHOOL CHILDREN
}

\author{
By C. J. HOLLISTER, D.D.S., Harrisburg, Pennsylvania
}

(Read before the Chicago Dental Society, January 19-21, 1922)

$\mathrm{E}$ VER since medical inspection of school children became an integral part of our public school system, attention has been focused on the teeth. This has been but natural, since irrespective of the location of a school or social status of the pupil, no physical defect occurs with such frequency as dental caries. Effort to correct this condition has resulted in the establishment of dental clinics in large numbers thruout the United States.

Many of these clinics have been in operation for ten years or more; therefore ample time has elapsed in which to judge their effectiveness. Those in a position to know assert that while dental clinics have been of great service, they are entirely inadequate for the work at hand. Their function has been to repair the damage incident to dental caries, and not to prevent its development. In communities where the dental clinic is operating, the call for service is so great, that the clinic is able to give little more than emergency relief of pain. For instance, a boy with an aching six-year molar can obtain immediate relief service, but his schoolmate with teeth just beginning to decay, but giving no trouble cannot get service until his teeth have decayed almost, if not entirely, beyond repair. Therefore the authorities, realizing that the dental problem among school children primarily requires preventive measures, have developed campaigns based on the simple principles of dental prophylaxis. Perhaps the best example of such a dental campaign is to be found in Bridgeport, Connecticut, where under the able direction of A. C. Fones a prophylactic dental service was installed about six years ago. The success attending this piece of work has long since taken it out of the class of experiments, and it now stands as a splendid demonstration of the practicability of dental prophylaxis.

The method our Department of Health is pursuing is based on the plan of Dr. Fones with modifications. 'The personnel of the Dental Division of the State Department of Health of Pennsylvania is as follows: a chief, an assistant, who is a dentist, two dental hygienists, and a chauffeur. The equipment used includes a completely equipped, specially built dental office, mounted on a truck chassis, in which the dentist operates. The dental hygienist's equipment consists of two fold ing or two portable dental chairs (army type), sterilizer, medicaments and hand instruments; no engines are used by the dental hygienists. The method of operation is as follows: First, a formal request is sent to the local school board for permission to demonstrate the feasibility, practicability, and great need for dental hygiene to their school children, without expense to them. When a school board has granted permission, forms are then forwarded to the local superintend- 
ent with the request that he select one or two fourth-grade rooms in which to conduct this demonstration, and that by the use of these forms he obtain the written consent of the parent or guardian of each child.

Upon the arrival of the demonstrative dental clinic, space is selected in the school building for the placing of the portable outfit of the dental hygienist. This is sometimes in a principal's office, vacant room, medical examination room, cloak room, the end of a hall, stair landing or even in the basement; in fact, wherever there is good light. Usually the setting up of the equipment takes about one-half hour. 'Then the children, two at a time, are brought to the dental hygienists to have their teeth cleaned. This occupies from twenty to thirty-five minutes for each child, and during this time, the dental hygienist talks to the child individually, telling him or her how, why and when he should use a toothbrush. During the period that the clinic operates in a schoolroom, the dental hygienist frequently goes to the classroom, giving talks on hygiene, both dental and general, and training the children in toothbrush drills. It is really wonderful, how the children respond to this work.

The object of our division in making visits to different communities thruout the state is not to care for a large number of children, but rather to show how all children can be given prophylactic treatment and education efficiently and economically.

During the demonstration period in a town, which usually occupies two weeks, arrangements are made for the dentist in charge to give talks before Rotary, Kiwanis, Lions, Civic and women's clubs, and similar organizations. Thru these organizations, an earnest effort is made to interest not only school authorities but all other leaders of the community, for such an innovation could scarcely be incorpor- ated into the school system without popular support. The local dentists are given prior notice of our intended visit, either thru local societies or individually. At the present time, the state finances only the demonstration, and we attempt to interest local authorities, sufficiently so that they will with local funds permanently establish this service for their children.

The results coming from our efforts have been very gratifying, in that approximately fifteen communities have taken up, in a permanent form, some kind of dental service for their school children, and all of the communities visited are seriously considering the problem. ;We feel very much encouraged to learn that we will finally attain our desire and slogan: "Clean mouths for all Pennsylvania's school children."

"A clean tooth never decays." Some authorities disagree on this statement, and I will not offer argument on the subject, except to mention the results of Dr. Fones' work in Bridgeport, where in six years dental caries in school children were reduced 50 per cent by prophylaxis and education. We can but agree that diet, prenatal and after birth, is a great factor in susceptibility to caries, and where that has been faulty we say "all the more is thoro prophylaxis essential.".

Duty of dentist to the public: Ethics is the professional application of the golden rule. If we have something that is good for the public to know, should we not on that basis give it to them? In other words, we should impress the words "importance of care of the mouth and teeth."

I desire to offer an illustration which I think proves without qualification that our activity should receive the undivided and enthusiastic co-operation and support of the dental profession, in that it shows a direct benefit professionally and financially to the profession. In starting out the campaign this fall, 
one community ignored all communications from my office. It being on my direct line of march I was desirous of opening the fall work there, for I knew from experience that should. we pass by, later, they would do all in their power to have us return. Two weeks before we started out, I called up the local superintendent of schools to ask what action had been taken on my request. He replied that it had been pigeon-holed. In a very half-hearted way we were asked to come. We went, and three weeks after we arrived they had a dental hygienist at work in their schools, funds for her salary, equipment and maintenance being provided by subscriptions from the Rotary and Civic clubs, Chamber of Commerce, and the local dentists. In less than a month after dental hygiene became a part of their school system the dentists formed a small local society, primarily to aid the dental hygienist program, but they immediately framed a minimum scale of prices, standard office hours with a half holiday, and no Sunday work. They also engaged a prominent dentist to give a clinic before them.

The financial benefits received are almost beyond belief. This particular town had suffered for a year or more, due to industrial depression of its main industry, which had been shut down for that period. When I first talked dental hygiene for the betterment of the condition of children, one of the leading members of the community said to me: "With business as it is in our town, it is going to be a problem, not of making conditions better for the children, but rather a problem of putting bread into their mouths to keep them alive." Having been in this town for two weeks or more I was able to reply in the following way: "In spite of the business depression that has affected your community, I have noticed that the candy stores, soda fountains, and moving-picture houses have been doing a splendid business, which is proof to me that if the public is really desirous of obtaining something it will find a way and we are here to make them want better health for their children." On a return visit to that community, a few weeks ago, I met with the local dental society, and everyone of them reported that they were very busy on pay patients, a large percentage of whom were school children. This condition prevails there, when thru our state at the present time the average dentist is not as busy as he could be.

In preparation for this meeting, I wrote to all of the communities where the dental hygienist is permanently at work, and with your permission I shall read a few extracts from replies received. From the superintendent of schools of West Chester, Pennsylvania: "Miss Lincoln has been at work for about six weeks, and has made herself a part of the school system of West Chester. She is an earnest, hard working, conscientious girl. I believe she is going to make for dental hygiene a place in our school system. I am greatly pleased with the reaction of the children and the attitude of the parents." From the superintendent of the schools of Johnstown, Pennsylvania: "Personally, I believe that the work is progressing successfully and that it is winning interest in the community. The hygienist averages about six children per day. She turns in weekly reports to me." From the executive secretary of the Bradford County Tuberculosis Association: "The teachers and parents are enthusiastic over this work. We are making fine progress." From the dentist to the school district of the city of Scranton: "The personnel last year was made up of the dentist and two dental hygienists. 'Last year 7,200 prophylaxis cases were cared for; 5,200 extractions, 350 fillings, and 53 public meetings were held. This year there 
are 9,500 children with 3,600 complete to date; 1,800 extractions, 300 fillings, and 20 public meetings. Last year there was so much persuasion; this year the children look for us and present themselves, pointing out the teeth which they wish out. That is a pleasing sign, is it not? A canvass of drug stores shows an increase of toothbrush and tooth paste sales of over 25 per cent. Teachers are now showing great interest in our work. We are seeing a great decline in the number of cavities in mouths where we have cleaned them up. We classify the mouths: clean, fair and foul. Last year, we did not have many in the clean class, but we had our share in the foul class. This year, I am proud to say that we have nearly abandoned the last class. The dentists of the town claim, that if we do nothing else but get the children in a nice frame of mind, we will do a wonderful service. We have very few refusals. The dentists are taking more interest in the work than ever. They see now that we are helping them. We have many favorable comments from all sources about our work."

At the National Meeting in Milwaukee last year, I learned of the work of Jackson, Mississippi, ${ }^{1}$ in obtaining correction of dental defects of 100 per cent

${ }^{1}$ Gladys Eyrich, "One Hundred Per Cent Good Mouths-How Obtained in the Public Schools of Jackson, Mississippi," Jour. Nat. Dental Assoc., (January, 1922), 3. of 1,674 children. Judging from my experience in the past few years that is "short of miraculous." The details of that plan I know are familiar to you. I carried the idea back to Pennsylvania, and it is now in operation in a number of places very successfully.

I want to present one other phase of dental service. A few days ago, one of our state nurses told me that the medical inspector had just finished examining a rural school just outside of Harrisburg, of eighty children, and that eighty children were in need of immediate dental service. One boy was suffering to such an extent that he needed relief. She had taken this boy to one of the local hospitals, where he was afforded only very temporary relief. There is a school dental dispensary, but that is not available for children outside of that school district; hence there was no way in which to relieve this suffering child. While this is a specific case, the conditions found there are not peculiar to that particular community. It is a condition found all over the country, and this is a problem which I believe should receive the attention of the National Association, and that that body should strive to find a probable solution. This last point is made without any plan to offer. "We are seeking light."

I might say that in our state this condition is becoming so acute that if the profession does not find a solution the state authorities will be compelled to. 